\title{
К истории создания органов госуправления фотосъемкой в первые годы советской власти
}

(по публикациям Г.М. Болтянского)

Олег Бакулин

В статье рассмотрены работы известного теоретика, историка фотографии Г.М. Болтянского, в которых затрагивается проблема формирования органов государственного управления фотосъемкой в первые годы советской власти. Наряду с опубликованными трудами Г.М. Болтянского в статье анализируются посвященные данной теме разделы черновика его программной книги «Очерки по истории фотографии в СССР (1939) из фондов Российского государственного архива литературы и искусства.

Ключевые слова: Г.М. Болтянский, ВФКО, фотосъемка, государственное управление.

DOI: 10.30547/mediaalmanah.6.2020.6272
@ Бакулин Олег Александрович кандидат исторических наук, доцент, заведующий кафедрой фотожурналистики и технологий СМИ факультета журналистики МГУ имени М.В. Ломоносова (г. Москва, Россия), obakulin@yandex.ru
Было бы неверным утверждать, что история фотографии первых лет советской власти была обделена вниманием исследователей, свидетельство чему - ряд публикаций, авторы которых в разные годы в той или иной степени затрагивали данный сюжет. Прежде всего речь идет о работах Г.М. Болтянского (1939), С.А. Морозова $(1958,1986)$, Л.Ф. Волкова-Ланнита (1971), В.М. Магидова (2005), В.Т. Стигнеева $(2005,2015)$, Н.С. Заковыриной (2008), А.Н. Макарова (2013), А.А. Логинова (2015), И.Ю. Чмыревой (2016), В.Н. Вальрана (2018), А.А. Литвина (2018) и др. Однако считать, что история фотографии этого времени изучена досконально, было бы заблуждением. Даже сегодня можно говорить о целом ряде тем, связанных с историей развития ранней советской фотографии, требующих тщательной разработки. К их числу уместно отнести проблему возникновения в Советской России первых органов управления фотосъемкой ${ }^{1}$.

Изучение многочисленных публикаций о фотографии, появившихся в 19201930 гг., позволяет говорить о том, что первым автором, который стал систематически затрагивать в своих работах данную тему, можно считать теоретика, историка фотографии Г.М. Болтянского. В этой связи следует назвать его книгу «Ленин и кино» (1925), а также статьи: «Фоторепортаж 
за 10 лет» (1927), «Фоторепортаж в России» (1928), «Советский фоторепортаж в годы гражданской войны» (1937) и др. Особое место в его творчестве занимает монография «Очерки по истории фотографии в СССР» (1939), которая, по справедливому замечанию исследователя Н.А. Станулевич, стала «основополагающим трудом для следующих поколений авторов» (2012: 85).

Эти публикации нельзя отнеси к числу научных исследований, а история создания органов государственного управления фотосъемкой не является их главной темой. Тем не менее они содержат важные для понимания проблемы факты и авторские оценки, особенно значимые в виду того, что Г.М. Болтянский имел непосредственное отношение к зарождению советской хроникальной фотографии: в частности, руководил работой отделов хроники в Петроградском кинокомитете (1918-1920 гг.) и Всероссийском фотокиноотделе (ВФКО) Наркомпроса (1920-1922 гг.)². Кроме того, он имел доступ к редким документам, которые отражали взгляды В.И. Ленина на фотографию как инструмент большевистской пропаганды, был лично знаком с государственными деятелями, имевшими отношение к управлению фотоделом - например, с народным комиссаром просвещения А.В. Луначарским, заведующим ВФКО Наркомпроса Д.И. Лещенко и др.

В трудах современных историков мы можем встретить критику некоторых положений Г.М. Болтянского о государственном управлении фотосъемкой. Так, А.А. Литвин отмечает, что под влиянием «Очерков по истории советской фотографии" сложилось неверное представление о влиянии Всероссийского фотокиноотдела (ВФКО) ${ }^{3}$ на развитие фотодела в период гражданской войны (Литвин, 2018: 33-34). Однако специальный анализ работ Г.М. Болтянского, в которых затрагивается история появления органов государственного управления фотосъемкой в первые годы советской власти, нам обнаружить не удалось. Данная статья призвана отчасти восполнить этот пробел. Преследуя данную цель, мы рассчитываем изучить специфику привлеченных автором источников; выяснить, о каких институтах идет речь и как автор характеризует их деятельность; рассмотреть, как представлена роль В.И. Ленина в руководстве фотосъемкой; провести сравнительный анализ соответствующих разделов программной работы Г.М. Болтянского «Очерки по истории фотографии в СССР» с черновым вариантом книги, хранящимся в фондах Российского государственного архива литературы и искусства (РГАЛИ).

\section{Ленинские указания о фотографии в книге «Ленин и кино»}

Характеризуя состояние ленинского наследия о кино, фотографии и радио, известный российский историк, источниковед В.М. Магидов отмечает, что В.И. Ленин не оставил ни одного специально посвященного им произведения. Данные сюжеты отражены в других документах - законодательных актах, к подготовке которых он имел отношение, статьях, выступлениях и проч. «Между тем, несмотря на это обстоятельство (а также фрагментарность ленинских высказываний, в большинстве случаев носивших мемуарный характер), ленинское наследие служило для нескольких поколений советских ученых как методологической основой, так и источником различного рода исследований по проблемам кино, фотографии и радиовещания», - отмечает автор (Магидов, 2005: 62).

Данные замечания можно отнести кленинским директивам о необходимости использования фотографии в пропаганде, которые, будучи опубликованными в книге Г.М. Болтянского «Ленин и кино» (1925), в последующие десятилетия не единожды цитировались историками. Прежде всего речь идет об опубликованном впервые ленинском распоряжении заведующему ВФКО Д.И. Лещенко (1920 г.) приготовить снимки с фотографий суда над министрами 
правительства А.В. Колчака. Другим источником является «Текст записи слов В.И. Ленина», направленный заместителю наркома просвещения Е.А. Литкенсу (1922 г.), в котором наряду с положениями о развитии кинодела встречается редкое ленинское указание, касающееся собственно фотографии: «показывать не только кино, но и интересные для пропаганды фотографии с соответствующими надписями» (Болтянский, 1925: 13-14).

Не будучи специально посвящена фотографии, данная работа для нас представляет интерес прежде всего в силу того, что дает некоторые представления о специфике управления фотосъемкой в первые годы советской власти. В частности, как можно заключить из текста распоряжения на имя Е.А. Литкенса, В.И. Ленин не был в полной мере осведомлен о деятельности Наркомпроса в управлении фотокиноделом, о чем говорят его фразы, с которых начинается опубликованный Г.М. Болтянским документ: «Какие функции в фотокиноделе остались за Наркомпросом? Кто в Наркомпросе заведует этим делом? Вызвать и поговорить с ним» (Болтянский, 1925: 13). Кроме того, приведенные документы, позволяют частично реконструировать механизм реализации ленинских распоряжений о фотографии. В связи с этим обращает на себя внимание, что принимавшиеся на уровне Председателя СНК РСФСР решения, адресовались заместителю наркома просвещения (Е.А. Литкенсу) и заведующему отделом ВФКО (Д.И. Лещенко), минуя их руководство. Из книги можно также получить представление о том, как были выполнены данные директивы. Так, относительно вышеупомянутого указания В.И. Ленина заведующему ВФКО Д.И. Лещенко, Г.М. Болтянский отмечает: «Всероссийским фотокиноотделом не было почти ничего выполнено в плане этого предложения Владимира Ильича» (Болтянский, 1925: 26)4. Что же касается ленинского поручения Е.А. Литкенсу, то цитируя А.В. Луначарского, автор пишет, что «письмо к Литкенсу... реальных результатов не имело» (Болтянский, 1925: 19). В таком случае выходит, что обе инициативы В.И. Ленина, касавшиеся фотографии, фактически остались на бумаге. Впрочем, как отмечает со ссылкой на слова А.В. Луначарского автор книги, нереализованными также оставались ленинские замыслы относительно кино: «каждый раз, в связи с указаниями Владимира Ильича, предпринимались те или иные шаги, созывались совещания, но ВФКО... дальше этого не шел» (Болтянский, 1925: 20).

\section{Контуры авторской концепции}

Если в книге «Ленин и кино» заинтересованность новой власти в фотографии иллюстрируется отдельными указаниями В.И. Ленина, то в статье «Фоторепортаж за 10 лет», вышедшей в журнале «Фотограф» осенью юбилейного 1927 г., фотография (точнее, «фоторепортажная съемка») рассматривается в качестве важного для советской власти направления работы, практическим результатом которого стало создание государственных органов, занимающихся фотосъемкой: «Пролетарское государство, с первых шагов оценившее значение фоторепортажной съемки для интересов революции, не могло не включить эту работу в орбиту своей деятельности. Период военного коммунизма характеризуется тем, что советская власть впервые во всем мире включает в свою деятельность с первых шагов, как один из важных видов работы, организацию государственных органов по фотографической съемке» (Болтянский, 1927: 348) 5 .

Как можно заключить из текста, своего рода развитием данного тезиса служит перечисление целого ряда учреждений, ведающих фотосъемкой. Речь идет о «больших отделах» фоторепортажа, созданных при Петроградском и Московском кинокомитетах, Всеукраинском фотокинокомитете, Фотоотделе Центропечати, Государственной фотографии ВЦИК и др. 
Отметим, что в отличие от ряда последующих работ Г.М. Болтянского, посвященных зарождению советской фотографии, первым институтом, существовавшим «сейчас же после Октябрьской революции», автор называет «первое государственное фотобюро», которое функционировало при Скобелевском просветительном комитете, созданном до прихода большевиков к власти (Болтянский, 1927: 349). Представляется значимой и другая деталь - упоминание о самостоятельной, «параллельно» государственным структурам, работе фотографов в рассматриваемый автором период (Болтянский, 1927: 349).

Опубликованная кдесятилетнему юбилею советской власти, данная статья содержит соответствующие торжественности момента оценки работы вышеназванных институтов. Так, автор отмечает, что Петроградский и Московский кинокомитеты (позже ВФКО) «вели большую работу по фотосъемке событий»; Фотоотдел Центропечати поводил «громадную фоторепортажную работу»; «не меньшее значение имела работа» Государственной фотографии ВЦИК и проч. (Болтянский, 1927: 349). Вместе с тем отметим, что столь высокая оценка деятельности государственных учреждений, в чью компетенцию входило руководство фотосъемкой, фактически ограничивается провозглашением НЭПа. Начиная с этого времени, отмечает автор, «государственные киноорганизации стали пренебрегать фотосъемочной работой и прекратили ее» (Болтянский, 1927: 349).

Можно сказать, что в данной работе были очерчены общие контуры авторского подхода к истории формирования органов государственного управления фотографией в первые годы советской власти. В последующих статьях этот подход конкретизировался, дополнялся новыми деталями, частично корректировался. Так, в статье «Фоторепортаж в России» (1928) Г.М. Болтянский упоминает о целях создания отделов фоторепортажной съемки при Московском и Петроградском кинокомитетах, которые сводились к фиксации революционных событий и явлений, а также агитации, как в стране, так и за ее пределами - «для правильной информации и рассеивания буржуазной клеветы за границей» (Болтянский, 1928: 190). Отметим также, что автор фактически ограничивает круг органов, занимающихся фоторепортажной съемкой в России, четырьмя институтами - наряду с вышеупомянутыми комитетами речь идет о фотоотделе Центропечати и «Фотографии ВЦИК» (Болтянский, 1928: 190).

Как можно заключить из текста статьи, важным критерием эффективной деятельности некоторых из этих учреждений для автора является количество произведенных снимков. В частности, Г.М. Болтянский приводит данные, согласно которым «продолжавшие существовать вплоть до 1922 г.» отделы фоторепортажной съемки при Петроградском и Московском комитетах, произвели «до 3000 негативов в Ленинградском ${ }^{6}$ кинокомитете и до 12000 негативов в Москве во всероссийском фотокиноотделе Наркомпроса» (Болтянский, 1928: 190)7. В качестве другого критерия автор выделяет содержательную ценность этих снимков. «Обширность репортажных фотосъемок периода военного коммунизма в Москве, Ленинграде и провинции была исключительной. Никогда еще до этого не было произведено такого колоссального по количеству и ценного по содержанию материала», - отмечает автор (Болтянский, 1928: 192). Наконец, своего рода признанием эффективности и важности проделываемой вышеназванными учреждениями работы выступает оценка их деятельности В.И. Лениным, выразившим свое отношение в ранее упомянутой фразе: «Показывать не только кино, но и интересные для пропаганды фотографии с соответствующими надписями» (Болтянский, 1928: 192)8.

Как и в статье «Фоторепортажза 10 лет», автор отмечает, что с началом новой 
экономической политики в истории советской фотографии наступил новый этап. Однако теперь данный сюжет подается им безоценочно: «С началом нэпа прекратилась фоторепортажная работа в государственных киноучреждениях. Ликвидируется и фотоотдел Центропечати. Остается лишь Фотография ВЦИК, но характер ее работ изменяется. Фотосъемка событий занимает в ней уже второе место. На первом месте стоят практические учрежденческие нужды» (Болтянский, 1928: 192-193).

Характерной чертой опубликованной к двадцатилетнему юбилею Октябрьской революции статьи Г.М. Болтянского «Советский фоторепортаж в годы гражданской войны» (1937) является увеличение списка центральных и местных органов управления фотосъемкой, отчасти за счет описания деятельности профильных военных и гражданских органов на Украине. Также обращает на себя внимание упоминание о “содействии и помощи», оказываемой в первые месяцы после прихода большевиков к власти «отдельным фотографам» со стороны ВЦИК, Совнаркома и Наркомпроса и военно-революционных комитетов (Болтянский, 1937: 9). Однако о характере такого взаимодействия в работе не сказано. Наконец, автор приводит скорректированные данные о проделанной Московским и Петроградским комитетами фотосъемке: «Свыше 15000 ценнейших негативов событий революции создал Московский фотокинокомитет за годы гражданской войны и свыше 5000 - Петроградский кинокомитет» (Болтянский, 1937: 9). Но вопрос о том, какие источники были доступны автору, вновь остается открытым ${ }^{9}$.

\section{«Очерки по истории фотографии в СССР»: ленинское наследие}

Особое внимание истории появления органов управления фотосъемкой в первые годы советской власти Г.М. Болтянский уделяет в книге «Очерки по истории фотографии в СССР», опубликованной в 1939 г. к столетию со дня изобретения фотографии. Данная работа представляет собой, как справедливо отмечал сам автор, «первую попытку дать в последовательном изложении историю фотографии в России и СССР за все сто лет со дня изобретения фотографии» (Болтянский, 1939: 8).

Работая над книгой, автор привлек значительный корпус источников и литературы: в частности, авторские наработки и личные связи, о чем свидетельствуют архивные материалы из его личного фонда: «Собственные материалы: изданные и неизданные работы, записи, цифры, факты и др[угие] историч[еские]. материалы. Новые материалы по личным связям: переписка со старыми и новыми фотохудожниками, деятелями, фотографич[еской] науки, руководителями фотопромышленности (ГОМЗ, ФЭД) $)^{10}$; личные встречи и беседы с молодыми и старыми работниками»11.

Черновая версия книги хранится в фонде Г.М. Болтянского в Российском государственном архиве литературы и искусства (РГАЛИ. Ф. 2057) и представляет собой датированный 1939 г.12 машинописный текст с авторской правкой, а также рукописные материалы к книге преимущественно справочного характера13. Черновик книги сгруппирован в четыре дела в соответствии со структуройтекста, включающейтри части, а также оглавление, список важнейших дат из истории фотографии и др.

Ключевое значение в опубликованном тексте «Очерков» имеет для нас авторское положение, согласно которому «практическая деятельность Наркомпроса и других советских учреждений, ведающих фотографией и кинематографией» в годы гражданской войны осуществлялась «на основе ленинских указаний и декрета о национализации фотокинодела» (Болтянский, 1939: 93). ${ }^{14}$ Очевидно, что данное положение актуализирует вопрос о содержании упомянутых автором источников.

Прежде всего это текст ранее опубликованной резолюции «О политической 
пропаганде и культурно-просветительной работе в деревне», «составленной при участии Ленина и Сталина», которая была принята на VIII съезде РКП(б) в марте 1919 г. и являлась, по словам автора, «одним из самых ранних послеоктябрьских общепринципиальных партийных документов, имевших отношение к фотографии как области идеологической практики» (Болтянский, 1939: 90). Вместе стем, как справедливо указывает сам Г.М. Болтянский, в тексте документа не содержится конкретных упоминаний относительно использования фотографий в культурно-просветительной работе в деревне: «В этой резолюции мы имеем косвенное указание [выделено нами. - О.Б.] на использование фотографии для коммунистической пропаганды при помощи волшебного фонаря, т.е. посредством показа фотографий в виде диапозитивов, а также посредством устройства выставок (в том числе и фотовыставок)» (Болтянский, 1939: 90).

Апеллируя к тексту резолюции, автор в качестве принципиально важного положения, определившего «характер, направление и формы применения фотографии в первые годы, последовавшие за Октябрьской революцией», 15 рассматривает тезис, который также не имеет прямого отношения к фотографии и носит исключительно декларативный характер: «Нет таких форм науки и искусства, которые не были бы связаны с великими идеями коммунизма и бесконечно разнообразной работой по созданию коммунистического хозяйства» (цит. по: Болтянский, 1939: 92)16. Примечательно, что сам автор указывал на декларативность цитируемого фрагмента (что отражено в хранящемся в фондах РГАЛИ черновом варианте книги, называя его «замечательным и ярким, декларативным и принципиальном тезисом резолюции», однако в самой книге речь идет лишь о «замечательном тезисе» 17 .

Среди источников, связанных с принятием В.И. Лениным решений в области фотографии, Г.М. Болтянский упоминает фрагмент из опубликованных в 1927 г. воспоминаний управделами СНК РСФСР В.Д. Бонч-Бруевича о предложении В.И. Ленина (1919 г.) производить съемку вскрытия мощей в Свято-Троицкой Сергиевой Лавре. Отметим, что в тексте воспоминаний, на которые ссылается Г.М. Болтянский, нет приводимых автором «Очерков» упоминаний о том, что кинокомитет «систематически снимает вскрытие мощей на кино и фото» [выделено нами. - О.Б.]. В.Д. БончБруевич лишь сообщает, что лично показывал В.И. Ленину «фотографии из киноленты, заснятые во время вскрытия мощей в Троице-Сергиевской лавре» (Бонч-Бруевич, 1927: 4).

В любом случае, анализ обоих текстов не позволяет однозначно говорить, что инициатива такой съемки исходила от В.И. Ленина. У В.Д. Бонч-Бруевича встречается такой сюжет: «Владимир Ильич всегда спрашивал: снимают ли киноленты, когда вскрывают мощи различных святых?» (Бонч-Бруевич, 1927: 4). У Г.М. Болтянского, опирающегося на текст В.Д. Бонч-Бруевича, акцент сделан на фотосъемке. При этом данный сюжет выглядит таким образом, что В.И. Ленин не знал, проводится ли такая работа: «В 1919 г. Владимир Ильич заинтересовался вопросом, фотографирует ли кто-либо вскрытие мощей. Когда ему сказали, что кинокомитет систематически снимает вскрытие мощей на кино и фото, В.И. Ленин, по свидетельству Бонч-Бруевича, потребовал показать ему эти снимки» (Болтянский, 1939: 92).

Помимо этого, в работе используются фрагменты цитировавшегося в книге «Ленин и кино» письма В.И. Ленина в ВФКО18 о необходимости изготовить снимки с негативов фотографий суда над министрами правительства А.В. Колчака19. При этом автор свидетельствует, что данная инициатива вследствие недостаточно высокого качества снимков не была реализована (Болтянский, 1939: 93). 
Наконец, еще одним источником, связанным с ролью В.И. Ленина в руководстве фотоделом в первые годы советской власти, является прежде опубликованная директива В.И. Ленина о необходимости «показывать не только кино, но и интересные для пропаганды фотографии с соответственными надписями». Однако из текста «Очерков» не ясно, как было реализовано ленинское указание (лишь в работе «Ленин и кино» (1925) со ссылкой на Луначарского находим упоминание, что письмо к Литкенсу, в котором содержалось ленинское указание, также «реальных результатов не имело» (Болтянский, 1925: 19)).

\section{Особенности государственного управления фотосъемкой}

Рассматривая деятельность созданных в первые годы советской власти органов управления фотосъемкой, Г.М. Болтянский вновь упоминает Московский и Петроградский кинокомитеты, созданные Наркомпросом «для государственного руководства фотокиноделом»: в частности, сформированные при них отделы фотосъемки текущих политических событий, которые автор именует «первыми государственными организациями по фотографической съемке событий». При этом, вероятно, желая сконцентрировать внимание читателя на важности именно «фотографического» направления в работе кинокомитетов, автор отказывается от сохранившейся в архивной версии книги ремарки о том, что «комитеты эти уделяли главное внимание кинематографии»20.

Как можно заключить из текста книги, в опубликованной версии «Очерков» автор решил подчеркнуть приоритетную роль Петроградского кинокомитета в организации советского фоторепортажа. Так, обращает на себя внимание, что из опубликованного варианта книги был исключен содержавшийся в ее черновой версии фрагмент о фоторепортажной работе Московского кинокомитета: «Московский кинокомитет и сосредотачивает всю свою деятельность в области фотографии на развитии государственного фоторепортажа»21.

Отметим, что в архивной версии текста фактически сравнивалась деятельность двух комитетов, причем не в пользу Московского, о чем может свидетельствовать указание Г.М. Болтянского на то, что Петроградский областной комитет развивал в области фотографии «более [выделено нами. - О.Б.] широкую деятельность»22. После того, как из опубликованной версии книги исчезла фраза о фоторепортажной работе Московской организации, очевидно, отпала и необходимость в сравнении работы двух комитетов - в «Очерках» речь идет лишь о «широкой деятельности» петроградцев (Болтянский, 1939: 93). Однако теперь в финальной версии книги появляется отсутствовавший в черновике тезис об особой роли Петроградского комитета в организации фоторепортажной съемки в Советской России: «Основной его [Петроградского комитета. - О.Б.] заслугой была организация советского фоторепортажа - то, что он создал съемочную базу в Смольном и начал выпускать первые сменные агитфотовитрины в разных районах Петрограда» (Болтянский, 1939: 93)23. В архивной версии текста акценты так расставлены не были - речь шла лишь об упоминании наряду с другими мероприятиями Петроградского кинокомитета созданной им «фотосъемочной базы» и «первых сменных агитфотовитрин» 24 .

Касаясь практической деятельности этих институтов, Г.М. Болтянский вновь корректирует данные о количестве произведенных ими снимков, отмечая, что с середины 1918 до 1921 г. Московским комитетом, а также образованным позднее на базе последнего ВФКО было выполнено более 12 тыс. съемок (негативов), а Петроградским - около 3 тыс. (Болтянский, 1939: 95). Значимым критерием эффективности работы этих институтов является содержательная важность съемки, т.к. многие из 
этих негативов представляют «исключительную историко-революционную ценность» (Болтянский, 1939: 95).

В книге фактически выкристаллизовывается роль ВФКО как эффективной государственной структуры, осуществлявшей разностороннюю деятельность в области фотодела25. Примечательно, что Г.М. Болтянский называет ВФКО «крупнейшей организацией фоторепортажа среди всех перечисленных» в книге 26 . Данный тезис автор фактически подкрепляет, подчеркивая активную вовлеченность организации в съемку событий гражданской войны, широкую географию работы фотографов ВФКО, съемку значимых политических событий (съездов Советов, конгрессов Коминтерна и проч.), а также использование отпечатков, выполненных с негативов фотографов ВФКО, для распространения как в стране, так и за ее пределами. Кроме того, он обращает внимание на агитационную, фотовыставочную деятельность Всероссийского фотокиноотдела Наркомпроса, участие отдела в национализации фотокинопредприятий и проч. (Болтянский, 1939: 94, 96-98).

Следуя сложившейся в его работахтрадиции, Г.М. Болтянский упоминает целый ряд учреждений, связанных с управлением фотосъемкой, ее организацией. В работе рассматриваются функции, практическая деятельность этих институтов, однако о характере их взаимодействия друг с другом зачастую речи не идет, что не позволяет говорить именно о системе органов управления. В книге впервые затрагивается вопрос о финансировании государством «фотоотделов и фотосъемочных баз при различных учреждениях», но речь идет лишь об упоминании, призванном подчеркнуть «огромное агитационно-пропагандистское значение», которое новая власть придавала фотографии (Болтянский, 1939: 98). Кроме того, в "Очерках» упоминается о московских, петроградских, а также украинских организациях, в чью компетенцию входило руководство и организация фотосъемкой, но вопрос о том, как осуществлялось управление в других регионах (в частности, силами ВФКО), специально не рассматривается. В работе упоминаются лишь отдельные региональные органы управления фотосъемой: в частности, фотоотделы при республиканских и губернских отделениях РОСТА, созданные «на периферии» (Болтянский, 1939: 95). В архивной версии книги также шла речь о «многих профессиональных портретистах на местах, сотнях фотографов провинции», которые занимались фоторепортажной работой на службе местных Советов, однако обнаружить данный сюжет в опубликованном варианте «Очерков» нам не удалось 27.

\section{Выводы}

Анализ публикаций Г.М. Болтянского, в которых затрагивалась история органов государственного управления фотосъемкой в первые годы советской власти, свидетельствует о том, что общие контуры авторской концепции, позднее нашедшей воплощение в его программной работе «Очерки по истории фотографии в СССР», сформировались уже во второй половине 1920 гг. В основе этой концепции лежал тезис об исключительной важности для советской власти фоторепортажной съемки, что выразилось, в частности, в создании многочисленных профильных государственных учреждений. В то же время работы 1920 гг. содержали элементы критики деятельности государственных структур, осуществляющих управление фотосъемкой, - Всероссийского фотокиноотдела Наркомпроса, различных киноогранизаций, «пренебрегающих фотосъемочной работой». В публикациях этого периода можно встретить упоминания об отдельных указаниях В.И. Ленина о фотографии, оставшихся нереализованными, о деятельности созданного до Октябрьской революции Скобелевского просветительного комитета, параллельной государственным 
учреждениям работе ряда фотографов. ВФКО. Каки впрежнихпубликацияхГ.М. БолВ появившихся в самом конце 1930 гг. «Очер- тянского, значительное место в авторских кахпо истории фотографии в СССР» история первых органов государственного управления претерпевает заметные изменения. В рамках авторской концепции в основе управления фотосъемкой оказываются отдельные ленинские указания и положения о фотографии, имевшие нередко декларативный характер. Особую роль в организации советского фоторепортажа на страницах книги приобретает Петроградский кинокомитет, в то время как "крупнейшей организацией фоторепортажа» становится построениях занимают многочисленные учреждения, в чью компетенцию входит управление фотосъемкой, а в качестве критериев их эффективной деятельности выступает количество произведенных кадров, их историческая важность и проч. В то же время встречавшаяся в прежних работах эпизодическая критика деятельности этих институтов фактически исчезает. История органов управления фотосъемкой в первые годы советской власти приобретает законченный вид.

\section{Примечания}

1 Под фотосъемкой мы имеем в виду основное направление фотографической практики, входившее в сферу интересов профильных учреждений в указанный период, - хроникальную (документальную) фотосъемку.

2 Болтянский Григорий Моисеевич // Гражданская война и военная интервенция в СССР. Энциклопедия. М.: Сов. энциклопедия, 1983. С. 70.

3 Всероссийский фотокинематографический отдел (ВФКО) образован на основании декрета СНК от 27 августа 1919 г. «О переходе фотографической и кинематографической [торговли и] промышленности в ведение Народного комиссариата просвещения» в целях «осуществления посредством фотографии и кинематографии научно-учебных, культурно-просветительных и агитационно-пропагандистских задач, а также для организации фотокиноторговли и промышленности, снабжения и распределения относящихся сюда технических средств и материалов». В соответствии с Постановлением Наркомпроса «О Всероссийском фотокинематографическом отделе (ВФКО) Наркомпроса», опубликованном 18 сентября 1919 г., «в исключительно ведении» ВФКО должно было находиться «все кинематографическое дело в пределах РСФСР».

4 Была изготовлена лишь серия снимков плохого качества, вследствие чего фотографии не были распространены. См.: Болтянский Г.М. Ленин и кино. С. 26.

5 Конкретно о роли В.И. Ленина в работе не упомянуто.

6 Так в тексте.

7 Автор не указывает, какие источники легли в основу его расчетов.

8 Описываемый автором в книге «Ленин и кино» (1925) контекст появления этого документа в данном случае не дается.

9 Соссылкой на фонды Наркомпроса, современный российский историкА.А. Литвин (2018: 36) указывает на содержащиеся в архивных документах данные о 10 тыс. негативах.

10 ГОМЗ - Государственный оптико-механический завод имени ОГПУ; ФЭД- вероятно, Харьковский промышленный комбинат имени Ф.Э. Дзержинского. 
11 РГАЛИ. Ф. 2057. Оп. 1. Д. 41. Л. 263.

12 Цифра «9» в обозначении года написана поверх другой цифры - вероятнее всего, «8». Это позволяет говорит о том, что работа над книгой велась ранее 1939 г.

13 РГАЛИ. Ф. 2057. Оп. 1. Д. 38-41.

14 В рукописи книги речь идето том, что деятельность Наркомпроса и соответствующих советских учреждений базировалась также на директиве из резолюции VIII съезда партии, а также «вышеуказанных задачах, поставленных Октябрьской революцией перед фотографией» (подр. об этом см.: РГАЛИ. Ф. 2057. Оп. 1. Д. 39. Л. 94).

15 В черновом варианте книги речь идет о том, что данное указание «определило характер, направление и формы использования фотографий советскими государственными фотокиноучреждениями, использования документальных фоторепортажных снимков для политической и хозяйственной пропаганды в период гражданской войны» (см.: РГАЛИ. Ф. 2057. Оп. 1. Д. 39. Л. 91-92).

16 Данная фраза выделена в тексте.

17 РГАЛИ. Ф. 2057. Оп. 1 Д. 39. Л. 91. «Другим важнейшим актом», связанным с участием В.И. Ленина в государственном руководстве фотоделом в первые годы советской власти, Г.М. Болтянский называет Декрет СНК «О переходе фотографической и кинематографической торговли и промышленности в ведение Народного комиссариата просвещения» от 27 августа 1919 г., напрямую не регламентирующий вопросы государственного управления фотосъемкой.

18 Как упоминалось выше, в книге «Ленин и кино» Г.М. Болтянский называет конкретного адресата этого распоряжения - заведующего ВФКО Д.И. Лещенко.

19 В «Очерках по истории фотографии в СССР» Г.М. Болтянский ссылается на публикацию документа в журнале «Советское кино» (1933. № 1-2. С. 8). В свою очередь, в качестве источника в “Советском кино» указана книга Г.М. Болтянского «Ленин и кино» (1925).

20 РГАЛИ. Ф. 2057. Оп. 1. Д. 39. Л. 94.

21 Там же. Л. 94-95.

22 Там же.

23 Инициатива в создании таких витрин принадлежала самому Г.М. Болтянскому. (см. подр.: Фотограф. 1927. № 11-12. С. 350-351).

24 РГАЛИ. Ф. 2057. Оп. 1 Д. 39. Л. 95.

25 Подр. об этом см.: А.А. Литвин (2018: 33-34).

26 Если обратиться к архивной версии книги, то можно увидеть, что «основной центральной и крупнейшей организацией, ведшей систематические плановые разнообразные фоторепортажные съемки в широком масштабе» автор называет Московский кинокомитет, переименованный в 1919 г. в ВФКО (подр. об этом см.: РГАЛИ. Ф. 2057. Оп. 1. Д. 39. Л. 99; Болтянский Г.М. Указ. соч. С. 95-96).

27 РГАЛИ. Ф. 2057. Оп.1 Д. 39. Л. 99.

\section{Библиография}

Болтянский Г.М. Ленин и кино. М.-Л.: Гос. изд-во, 1925.

Болтянский Г.М. Очерки по истории фотографии в СССР. М.: Госкиноиздат, 1939.

Болтянский Г.М. Советский фоторепортаж в годы гражданской войны // Сов. фото. 1937. № 11. С. 8-9. 
Болтянский Г.М. Фоторепортаж в России // Фотографический Альманах. 1928. С. 182-193. Болтянский Г.М. Фоторепортаж за 10 лет // Фотограф. 1927. № 11-12. С. 347-353.

Бонч-Бруевич В.Д. Ленин и кино - по личным воспоминаниям // Кино-фронт. 1927. № 7-8. С. 2-5.

Вальран В. Советская фотография 1917-1955. - СПб.: Изд-во К. Тублина («Лимбус Прес(»), 2016.

Гражданская война и военная интервенция в СССР. Энциклопедия. М.: Сов. энциклопедия, 1983.

Заковырина Н.С. Особенности развития отечественной фотожурналистики 1920-х-1930-х годов и журнал «Советское фото»: дис. ... канд. филол. наук. СПб., 2008.

Литвин А.А. Российская фотография в годы гражданской войны // Гражданская война в России в фотографиях и кинохронике. 1917-1922: альбом / Федеральное архивное агентство РГАКФД. М.: Кучково поле, 2018. С. 33-40.

Логинов А.А. Искусство реальности: фотография рубежа XIX-XX веков. M.: photoHelpers, 2015.

Магидов В.М. Кинофотофонодокументы в контексте исторического знания. М.: Рос. гос. гуманит. ун-т, 2005.

Макаров А.Н. Информационно-пропагандистское сопровождение индустриализации 1929-1941 гг. средствами советского фоторепортажа (на материалах Магнитогорска): дис. ... канд. филол. наук. Челябинск, 2013.

Морозов С.А. Советская художественная фотография. М.: Искусство, 1958.

Морозов С.А. Творческая фотография. М.: Планета, 1986.

Стасюлевич Н.А. Русская историография фотографии // Клио. 2012. № 9 (69). С. 85-87.

Стигнеев В.Т. Век фотографии. 1894-1994. Очерки истории отечественной фотографии. М.: КомКнига, 2005.

Стигнеев В.T. Зарождение советской фотографии: 1920-е годы. M.: URSS, 2015.

Чмырева И.Ю. Очерки по истории российской фотографии. М.: Индрик, 2016. 